\title{
Using high-pressure torsion to process an aluminum-magnesium nanocomposite through diffusion bonding
}

\author{
Megumi Kawasaki ${ }^{\text {a) }}$ \\ Division of Materials Science and Engineering, Hanyang University, Seoul 133-791, South Korea; and \\ Departments of Aerospace and Mechanical Engineering and Materials Science, University of Southern California, \\ Los Angeles, California 90089-1453, USA \\ Byungmin Ahn \\ Department of Energy Systems Research, Ajou University, Suwon 443-749, South Korea; and Department of \\ Materials Science and Engineering, Ajou University, Suwon 443-749, South Korea \\ HanJoo Lee \\ Division of Materials Science and Engineering, Hanyang University, Seoul 133-791, South Korea
}

Alexander P. Zhilyaev

Institute for Metals Superplasticity Problems, Ufa 450001, Russia; and Research Laboratory for Mechanics of New Nanomaterials, Saint Petersburg State Polytechnical University, St. Petersburg 195251, Russia

Terence G. Langdon

Departments of Aerospace and Mechanical Engineering and Materials Science, University of Southern California, Los Angeles, California 90089-1453, USA; and Materials Research Group, Faculty of Engineering and the Environment, University of Southampton, Southampton SO17 1BJ, UK

(Received 7 March 2015; accepted 7 August 2015)

Disks of commercial Al-1050 and ZK60A alloys were stacked together and then processed by conventional high-pressure torsion (HPT) through 1 and 5 turns at room temperature to investigate the synthesis of an Al-Mg alloy system. Measurements of microhardness and observations of the microstructures and local compositions after processing through 5 turns revealed the formation of an ultrafine multi-layered structure in the central region of the disk but with an intermetallic $\beta-\mathrm{Al}_{3} \mathrm{Mg}_{2}$ phase in the form of nano-layers in the nanostructured $\mathrm{Al}$ matrix near the edge of the disk. The activation energy for diffusion bonding of the $\mathrm{Al}$ and $\mathrm{Mg}$ phases was estimated and it is shown that this value is low and consistent with surface diffusion due to the very high density of vacancy-type defects introduced by HPT processing. The results demonstrate a significant potential for making use of HPT processing in the preparation of new alloy systems.

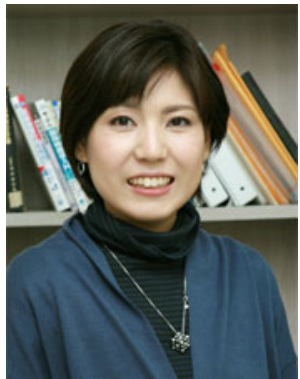

Megumi Kawasaki

\section{INTRODUCTION}

The processing of metals through the application of severe plastic deformation (SPD) has attracted much attention for the production of ultrafine-grained metals

Contributing Editor: Jörg F. Löffler

a) Address all correspondence to this author.

e-mail: megumi@hanyang.ac.kr

DOI: $10.1557 / \mathrm{jmr} .2015 .257$
Megumi Kawasaki is an Associate Professor in the Division of Materials Science \& Engineering at Hanyang University, South Korea, where she joined the faculty as an Assistant Professor in 2012.

Megumi obtained her B.Eng. degree from Osaka Prefecture University in Japan in 2002 and then received an M.S. degree in 2004 and Ph.D. degree in 2007 in Materials Science at the University of Southern California.

Her research interests lie in the area of the synthesis and properties of ultrafine-grained and nanostructured materials processed by severe plastic deformation. She has collaborated actively with many researchers around the world and has published over 100 papers in peer-reviewed journals through her Ph.D. research and in the years after her Ph.D. She is currently listed on ISI Web of Science with an h-index of 23.

having grain sizes in the submicrometer or even the nanometer range. ${ }^{1}$ Among the various SPD techniques, high-pressure torsion (HPT) provides the potential for achieving true nanometer grains in bulk metals. ${ }^{2}$ In HPT, a disk is strained under a high compressive pressure with concurrent torsional straining and the processing is usually conducted at room temperature which is effective even for difficult-to-deform materials such as Mg alloys. ${ }^{3}$ Numerous reports are now available describing the 
application of HPT to a range of pure metals and simple alloys and they demonstrate an enhancement of the physical and mechanical characteristics through significant grain refinement and the intensive introduction of defects. ${ }^{2,4}$

A critical limitation in HPT processing is that the imposed strain within the disk sample is significantly inhomogeneous. Specifically, when a disk is strained by conventional HPT, the shear strain, $\gamma$, is given by a relationship of the form ${ }^{5}$

$$
\gamma=\frac{2 \pi N r}{h}
$$

where $N$ is the number of HPT revolutions and $r$ and $h$ are the radius and thickness of the disk, respectively. Therefore, it is apparent from Eq. (1) that the torsional straining imposed within the disk sample is dependent upon the distance from the center of the disk and there is even zero straining at $r=0$ during processing. This suggests that there is an inevitable inhomogeneity both in the microstructure and in the hardness in HPT disk samples after processing. Nevertheless, early experiments demonstrated that high numbers of HPT revolutions and/or high applied pressures are effective in producing reasonably homogeneous microstructures and homogeneous values for the microhardness throughout the disks. ${ }^{6-8}$

The light-weight metals of $\mathrm{Al}$ and $\mathrm{Mg}$ are widely used in structural applications in the automotive, aerospace, and electronic industries but improvements in the mechanical properties of these metals would accelerate their usage in future applications. Combinations of different SPD processing techniques are available to enhance the upper limit of mechanical properties of a specific alloy ${ }^{9-13}$ but it is also important to study achieving superior properties by bonding dissimilar metals through a procedure such as fusion welding. Alternatively, processing by HPT was applied recently for the consolidation of metal powders and for fabricating dissimilar metallic systems based on aluminum and magnesium: for example, $\mathrm{Al}-\mathrm{Fe},{ }^{14} \mathrm{Al}-\mathrm{Mg},{ }^{15} \mathrm{Al}-\mathrm{Ni},{ }^{16}$ $\mathrm{Al}-\mathrm{Ti},{ }^{17} \mathrm{Al}-\mathrm{W},{ }^{18,19}$ and $\mathrm{Mg}-\mathrm{Zn}-\mathrm{Y}^{20}{ }^{20}$ Nevertheless, the practical difficulties associated with these processes include a requirement for a high processing temperature, ${ }^{16,17,19,20}$ the need for a two-step process of cold/hot compaction prior to consolidation by $\mathrm{HPT}^{18}$ and the inherent damage that may be introduced in the HPT anvils because of the stacking of fine hard powders in the depressions on the anvil surfaces.

Considering the processes for bonding of dissimilar metals, cladding-type metal working is generally utilized by pressing or rolling dissimilar bulk metals together under a high pressure as in the roll-bonding process. ${ }^{21-25}$ This approach was also developed using the accumulative roll bonding (ARB) process ${ }^{26}$ but the essential drawback of the processed metal plate after ARB involves the anisotropic mechanical response which is dependent upon the rolling direction and the through-thickness direction. ${ }^{27}$

A very recent report demonstrated a solid-state reaction in an $\mathrm{Al}-\mathrm{Cu}$ system through the bonding of semicircular halfdisks of $\mathrm{Al}$ and $\mathrm{Cu}$ through HPT at ambient temperature for up to 100 turns $^{28}$ and the vision of architecturing hybrid metals through HPT was discussed using computational calculations. ${ }^{29}$ Accordingly, the present research was initiated to examine the alternative possibility of achieving direct diffusion bonding of $\mathrm{Al}$ and $\mathrm{Mg}$ disks through conventional HPT processing for a short period of time. A very recent study showed the first demonstration of diffusion bonding of separate $\mathrm{Al}$ and $\mathrm{Mg}$ disks by HPT for 10 turns and the processed disk recorded very high specific strength attained by a combination of grain refinement, solution strengthening, and precipitation hardening. ${ }^{30} \mathrm{How}-$ ever, the microstructural change through HPT generally occurs in the early stage of processing and the essential issue of the diffusion bonding of these dissimilar metal disks was not well understood in the earlier study. Therefore, the present research was aimed specifically to examine the feasibility of the formation of a multi-layered $\mathrm{Al}-\mathrm{Mg}$ system through the bonding of $\mathrm{Al}$ and $\mathrm{Mg}$ disks through HPT for 5 turns and the resultant microstructure was evaluated by estimating the diffusivity of $\mathrm{Mg}$ atoms in an $\mathrm{Al}$ phase under the specific processing conditions of 5 turns. As will be demonstrated, the results provide a direct confirmation of the potential for making use of HPT for the formation of an intermetallic-based metal matrix nanocomposite in the nanostructured multi-layered $\mathrm{Al}-\mathrm{Mg}$ disk through diffusion bonding for 5 HPT turns at room temperature.

\section{EXPERIMENTAL PROCEDURES}

Two separate metals of aluminum and magnesium were used in the present experiments. Specifically, they were a commercial purity $(99.5 \%)$ aluminum Al-1050 alloy containing $0.40 \mathrm{wt} \% \mathrm{Fe}$ and $0.25 \mathrm{wt} \% \mathrm{Si}$ as a major impurity with $<0.07 \mathrm{wt} \% \mathrm{Zn}$ and $<0.05 \mathrm{wt} \%$ of $\mathrm{Cu}$ and $\mathrm{Mg}$ as a minor impurity and a commercial ZK60 magnesium alloy containing $4.79 \mathrm{wt} \% \mathrm{Zn}$ and $0.75 \mathrm{wt} \% \mathrm{Zr}$. Both of these alloys were received as bars after extrusion with diameters of $\sim 10 \mathrm{~mm}$. Each bar was cut and sliced into disks having thicknesses of $\sim 1.2 \mathrm{~mm}$ and these disks were polished to have final thicknesses of $\sim 0.83 \mathrm{~mm}$.

The processing of these materials was conducted using a quasi-constrained HPT facility ${ }^{31,32}$ at room temperature in a conventional manner ${ }^{33}$ except that the pressing simultaneously involved two separate materials. Thus, separate disks of the $\mathrm{Al}$ and $\mathrm{Mg}$ alloys were placed in the order of $\mathrm{Al} / \mathrm{Mg} / \mathrm{Al}$ into the depression on the lower anvil. It should be noted that the stacking of metal disks was prepared without using any glue or metal brushing treatment. A schematic illustration of the sample set-up for HPT 
processing is shown in Fig. 1 where a ZK60 magnesium alloy is placed between two Al-1050 disks. ${ }^{30}$ Two separate piles of three disks were processed through HPT under an applied pressure, $P$, of $6.0 \mathrm{GPa}$ for total numbers of revolutions, $N$, of 1 and 5 turns using a constant rotational speed of $1 \mathrm{rpm}$.

Following processing, the two disks were cut vertically along their diameters to give two semicircular disks for each testing condition. One vertical cross-section from each disk was then polished, chemically etched using Keller's etchant and examined by optical microscopy (OM). Subsequently, values of the Vickers microhardness, $H_{\mathrm{v}}$, were recorded over the vertical cross-sections of the disks after HPT for 1 and 5 turns using a Shimazu HMV-2 facility (Shimazu, Tokyo, Japan) with a load of 50 gf. These individual microhardness values were recorded following a rectilinear grid pattern with an incremental spacing of 0.2 $\mathrm{mm}$ and they were used to construct color-coded contour maps displaying the hardness distributions within the vertical cross-sections. For the highly strained disk after 5 turns, an overview of the semicircle disk surface was also observed by $\mathrm{OM}$ after slight polishing of the outer rough surface using a Buehler VibroMet 2 (Buehler, Lake Bluff, Illinois) with $0.06 \mu \mathrm{m}$ colloidal silica suspension under $60 \%$ vibration amplitude of the equipment maximum.

The vertical cross-section of the other semicircular disk processed by HPT for 5 turns was polished mechanically and an elemental analysis was conducted using energydispersive X-ray spectroscopy (EDS) in a field emission scanning electron microscope (FE-SEM), FEI Nova NanoSEM 450 (FEI Company, Hillsboro, Oregon). The detailed microstructure was investigated by FE-SEM, JEOL JSM6700F (JEOL Ltd., Tokyo, Japan), in the peripheral region near the outer edge of the disk on the vertical cross-section after preparing using a broad ion beam cross-section polisher, JEOL IB-09020CP (JEOL Ltd., Tokyo, Japan), with $6 \mathrm{kV}$ Ar ion beam and $\pm 30^{\circ}$ swing angle of specimen stage to minimize beam striations on the strain-free polished surface.

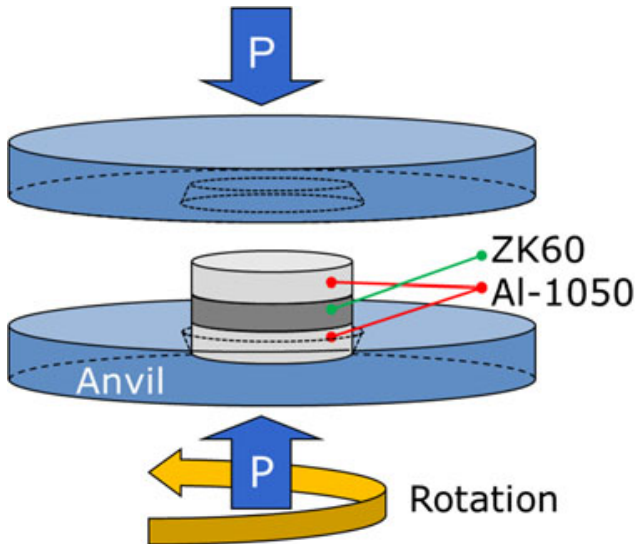

FIG. 1. Schematic illustration of the sample set-up for HPT processing. ${ }^{30}$
An X-ray diffraction (XRD) analysis was performed using a Rigaku UltimaIV XRD (Rigaku, Tokyo, Japan) on the slightly polished disk surface after HPT through 5 turns. The examination used a $\mathrm{Cu} \mathrm{K}_{\alpha}$ radiation with a scanning speed of $3 \% \mathrm{~min}$ and a step interval of $0.01^{\circ}$. Additional microstructural analysis was conducted by transmission electron microscopy (TEM) using a spherical aberration (Cs) corrected JEOL JEOM-2100F (JEOL Ltd., Tokyo, Japan) with $200 \mathrm{kV}$ accelerating voltage for a specimen prepared by an in situ lift-out technique using OmniProbe 200 and an Omni gas injection system (Oxford Instruments, Dallas, Texas) in a focused ion beam (FIB), JEOL JIB4500 (JEOL Ltd., Tokyo, Japan). High resolution compositional maps were obtained from specific areas of interest using Oxford EDS with $\mathrm{Si}(\mathrm{Li})$ detector in a scanning TEM (STEM) mode.

\section{EXPERIMENTAL RESULTS}

\section{A. Overview of the synthesized microstructure in an Al-Mg alloy system after HPT}

Figure 2 shows microstructure of the Al-Mg multilayered disks after HPT at room temperature where (a) provides overview montages of the vertical cross-sectional planes after 1 turn (upper) and 5 turns (lower) taken by $\mathrm{OM}$ and (b) and (c) show the microstructures in high magnification taken by OM and SEM, respectively, in the areas of the red rectangles at the center and edge of the disk after 5 turns as indicated in Fig. 2(a): for the OM images, the bright regions denote the Al-rich phase and the dark regions correspond to the $\mathrm{Mg}$-rich phase.

It is readily apparent that, after HPT for 1 turn as shown in the upper image in Fig. 2(a), the three disks of $\mathrm{Al}$ and $\mathrm{Mg}$ are bonded together without any segregation and the initial total height of $\sim 2.5 \mathrm{~mm}$ is reduced to an overall thickness of $\sim 0.83 \mathrm{~mm}$ through HPT processing. Due to the bonding of the $\mathrm{Al}$ and $\mathrm{Mg}$ phases, an $\mathrm{Al}-\mathrm{Mg}$ multi-layered microstructure is formed throughout the diameter of the disk after HPT for 1 turn. Although layered structures are consistently observed in metals processed by ARB, a significant difference in the HPT disk in Fig. 2(a) is that the $\mathrm{Al}$ and $\mathrm{Mg}$ phases extend horizontally but the $\mathrm{Mg}$ disk is necked and fragmented by the torsional straining so that the magnesium appears as islands. These islands of the Mg phases are slightly larger and thicker close to the center of the disk and they become thinner in the peripheral region. It should be noted that the $\mathrm{Al}-\mathrm{Mg}$ multi-layered microstructure is different from the earlier report using two semi-circular disks of pure $\mathrm{Al}$ and pure $\mathrm{Cu}$ where these two phases were separated without any phase fragmentation after processing by HPT for 1 turn under an applied pressure of $6.0 \mathrm{GPa}^{28}$

Processing by HPT for 5 turns produces an $\mathrm{Al}-\mathrm{Mg}$ multi-layered disk with a unique microstructural distribution 

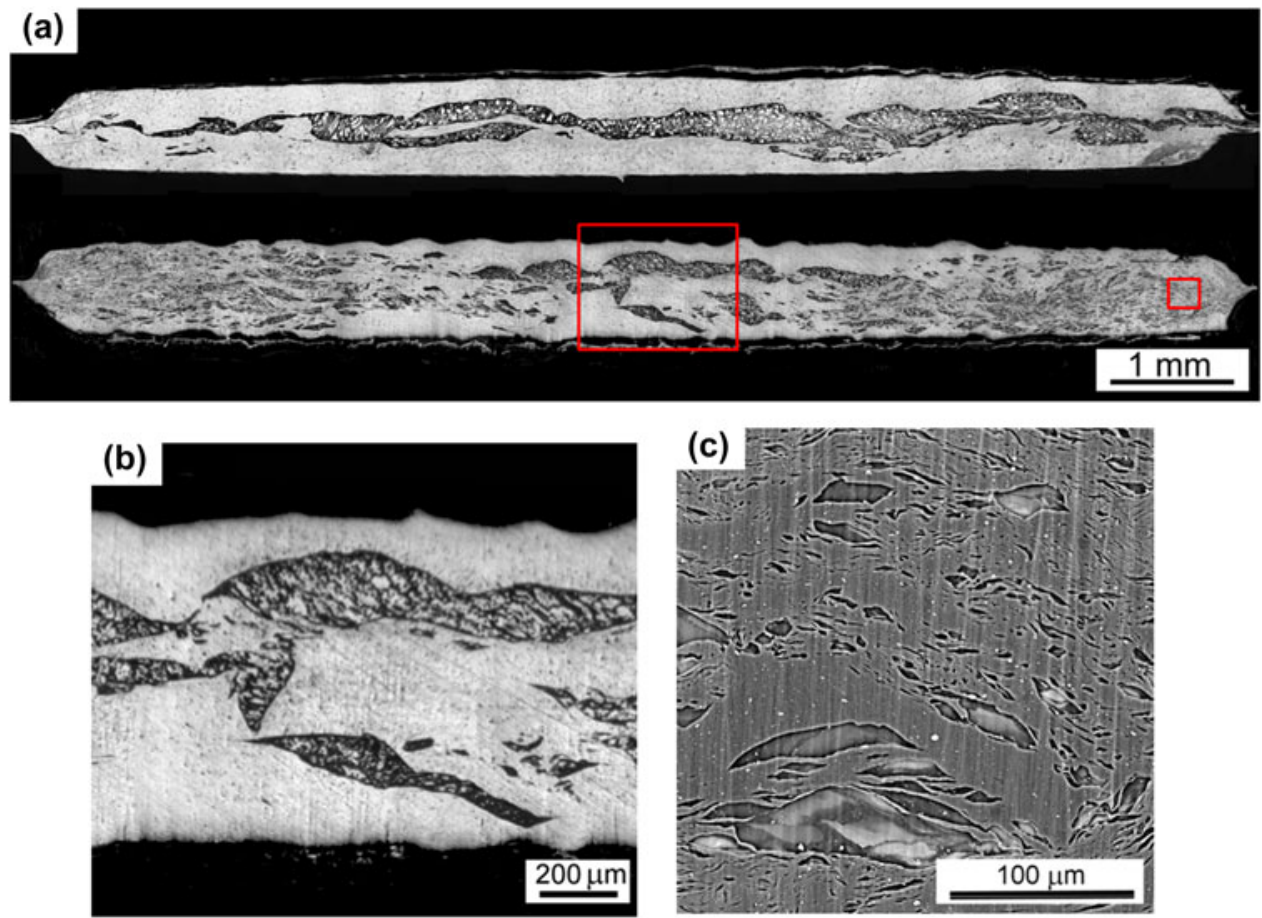

FIG. 2. (a) An overview of the vertical cross-sectional planes of the Al-Mg multi-layered disks after HPT at room temperature under a pressure of 6.0 GPa through 1 turn (upper) and 5 turns (lower); (b) and (c) give the microstructures taken in the areas of the red rectangles after 5 turns as shown in (a) at the center and edge of the disk, respectively.

as shown in the lower image in Fig. 2(a) and in Figs. 2(b) and 2(c). Specifically, two different microstructural features are clearly visible on the vertical cross-section after 5 turns depending upon the radial distance, $r$, from the center of the disk. First, in the central region at $r \approx 2.5 \mathrm{~mm}$ there are relatively thick stacked layers up to $\sim 200 \mu \mathrm{m}$ in thickness for the Mg phase between the $\mathrm{Al}$ phases. This multi-layered microstructure is shown at a higher magnification in Fig. 2(b) and the microstructural feature is essentially similar to the disk after HPT for 1 turn as shown in the upper image in Fig. 2(a). Second, the remainder of the disk after 5 turns consists of a homogeneously distributed very fine $\mathrm{Mg}$ phase confined within an Al matrix and this is especially evident in the SEM micrograph taken at the peripheral region as shown in Fig. 2(c) where the compression direction is vertical. In the SEM image, the darker phase corresponds to $\mathrm{Mg}$ and this phase is thin with widths of less than $\sim 5 \mu \mathrm{m}$ and it is elongated reasonably normal to the compression axis and aligned in the shear direction. Careful inspection showed that there is a homogeneously distributed fine $\mathrm{Mg}$ phase visible from $r \approx 2.5-3.0 \mathrm{~mm}$ to the outer edge of the disk where it follows from Eq. (1) that this region received shear strains, $\gamma$, from $\sim 120$ to 200 after HPT through 5 turns. A gradation in distribution of $\mathrm{Mg}$ layers within the $\mathrm{Al}$ matrix is also apparent on the polished disk surface after HPT for 5 turns as shown in Fig. 3 where the brighter phase denotes $\mathrm{Mg}$ and the dark

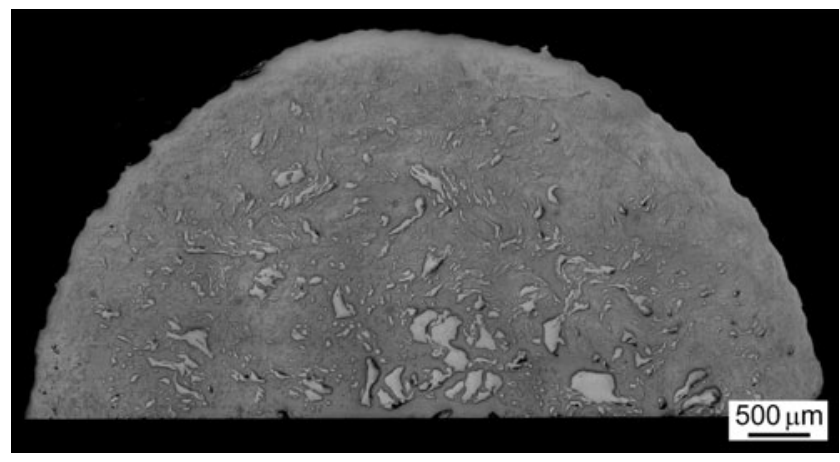

FIG. 3. A semi-circle surface of the polished disk after HPT for 5 turns.

region denotes $\mathrm{Al}$. A relatively large size of $\mathrm{Mg}$ phases with diameters of $200-300 \mu \mathrm{m}$ remain in the central region up to $r \approx 2.5 \mu \mathrm{m}$ and the numbers of small thin $\mathrm{Mg}$ phases are equally spread up to $r \approx 3.5-4.0 \mu \mathrm{m}$ whereas much smaller $\mathrm{Mg}$ phases shown in Fig. 2(c) at the peripheral region are not visible at the magnification used for Fig. 3.

Figure 4 shows the results of the EDS analysis at the center of the Al-Mg disk after 5 turns where the scanned window and the interdiffusion curves of the $\mathrm{Al}$ and $\mathrm{Mg}$ atoms are given at the upper and lower positions, respectively. It is apparent that the $\mathrm{Al}$ and $\mathrm{Mg}$ atoms diffuse into each other at the interface during HPT and the diffusion length is measured as $\sim 2.5 \mu \mathrm{m}$ where the 
layers of the $\mathrm{Mg}$ phase have thicknesses of a few hundred micrometers in the compressive direction at the center of the disk. A similar measurement was also performed for the relatively large elongated $\mathrm{Mg}$ phases having thicknesses of $\sim 5-10 \mu \mathrm{m}$ at the edge of the disk and an intermixing of $\mathrm{Al}$ and $\mathrm{Mg}$ atoms was observed with a diffusion length of $\sim 1-2 \mu \mathrm{m}$. The SEM micrographs and EDS analysis demonstrate clearly that there is no evidence for any cavity formation in either the $\mathrm{Al}$ or $\mathrm{Mg}$ phases throughout the disk where the formation of cavities may occur due to the Kirkendall effect in diffusion couples when the diffusivities are significantly different. $^{34,35}$

(a)
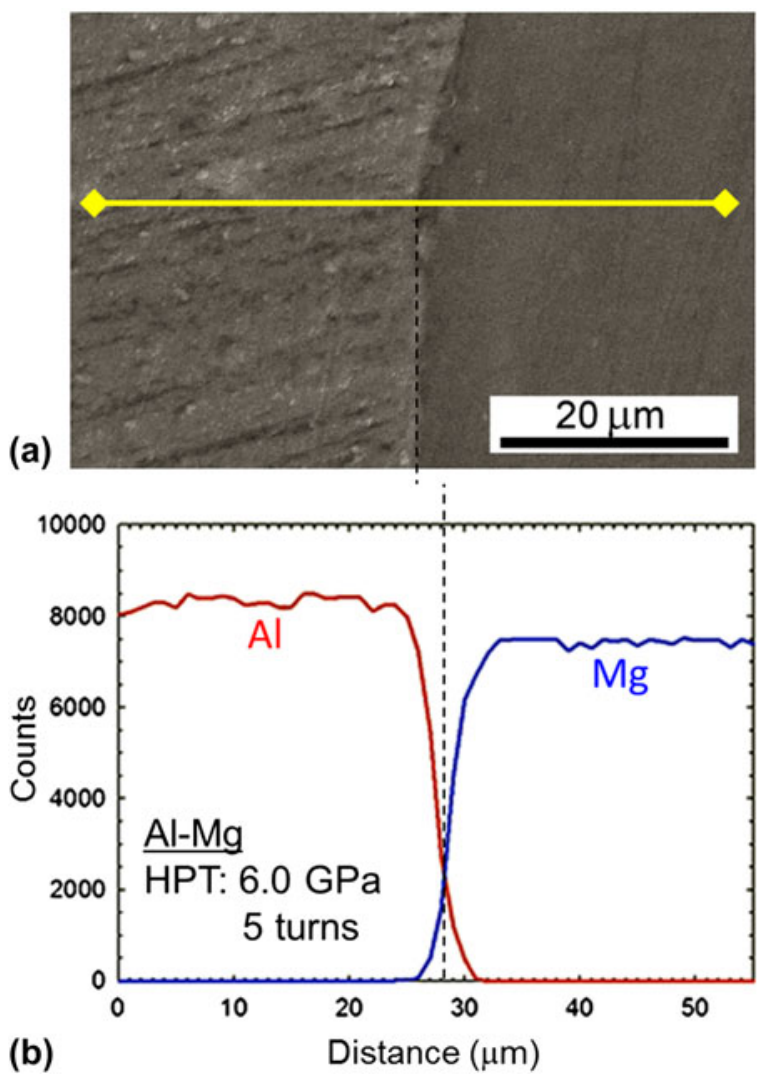

FIG. 4. (a) The EDS results with a scanned microstructure and (b) the diffusion curves of $\mathrm{Al}$ and $\mathrm{Mg}$ atoms measured at the center of the $\mathrm{Al}-\mathrm{Mg}$ disk after HPT under a pressure of $6.0 \mathrm{GPa}$ for 5 turns.

\section{B. Microhardness distribution and XRD analysis}

The distribution of microhardness on the vertical crosssections of the disks is shown in the color-coded contour maps in Fig. 5 for the $\mathrm{Al}-\mathrm{Mg}$ multi-layered disks processed by HPT for 1 (upper) and 5 turns (lower). The values of the hardness are shown in the key on the right in Fig. 5. For reference, the saturated $H_{\mathrm{v}}$ values were $\sim 63-65$ for Al-1050 (Ref. 36) and $\sim 105-110$ for the ZK60 alloy $^{37}$ after HPT for 5 turns under $6.0 \mathrm{GPa}$ and these values were reasonably saturated across the disk diameters without any evidence for the hardness gradations which are often present along the diameters of disks in the early stages of HPT. ${ }^{38,39}$ The unique distribution of hardness after 10 turns was described in a recent report. ${ }^{30}$

The hardness distribution for the disk after HPT for 1 turn shows a distribution of $H_{\mathrm{v}}$ of $\sim 60-100$ throughout the vertical cross-sections and the higher hardness values of $\sim 90-100$ tend to appear on the Mg layers with lower hardness of $\sim 60$ recorded on the $\mathrm{Al}$ matrix phase. After 5 turns, it is apparent that the central region in the disk containing the thick layered phases shows a lower hardness of $\sim 60-70$ which is consistent with the hardness of the Al-1050 alloy after HPT for 5 turns. ${ }^{36}$ However, there are significantly higher hardness values in the peripheral regions where there is a homogeneous mixture of the fine $\mathrm{Al}-\mathrm{Mg}$ phases as shown in Fig. 2(c). Thus, in the peripheral region the values of $H_{\mathrm{v}}$ reach a maximum of $\sim 130$ which is even higher than $\sim 105-110$ for the ZK60 alloy after HPT for 5 turns.

The unexpected high hardness is also visualized when plotting the hardness variations along the diameters of the Al-Mg disks after HPT for 1 and 5 turns and the plot is shown in Fig. 6 where these values were measured at the mid-section in the height direction on each disk. For comparison purposes, the map includes the hardness ranges of $\sim 63-65$ for Al-1050 (Ref. 36) and $\sim 105-110$ for the ZK60 alloy $^{37}$ after HPT for 5 turns in gray and yellow markers, respectively. As was shown in Fig. 5, the hardness values after 1 turn of HPT are within 60-100 and this wide variation within the disk is due to the measurement locations on different phases of $\mathrm{Al}$ or $\mathrm{Mg}$. However, it is interesting

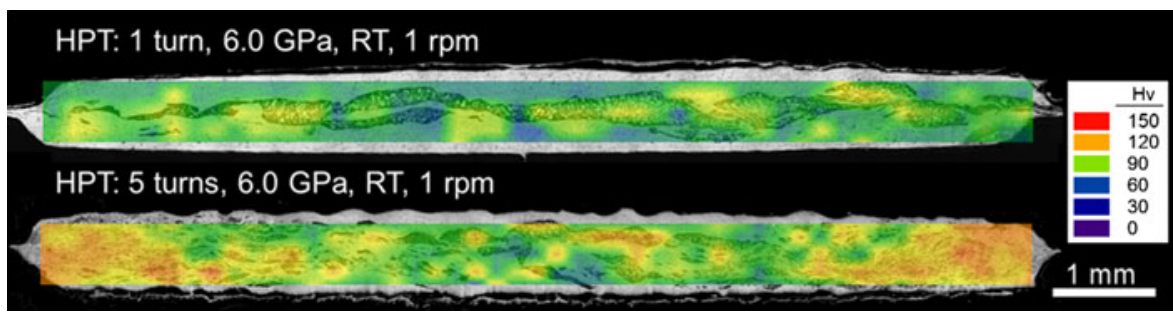

FIG. 5. Color-coded contour maps of the Vickers microhardness for the Al-Mg system after HPT for 1 turn (upper) and 5 turns (lower); the values associated with the various colors are given in the color key at right. 


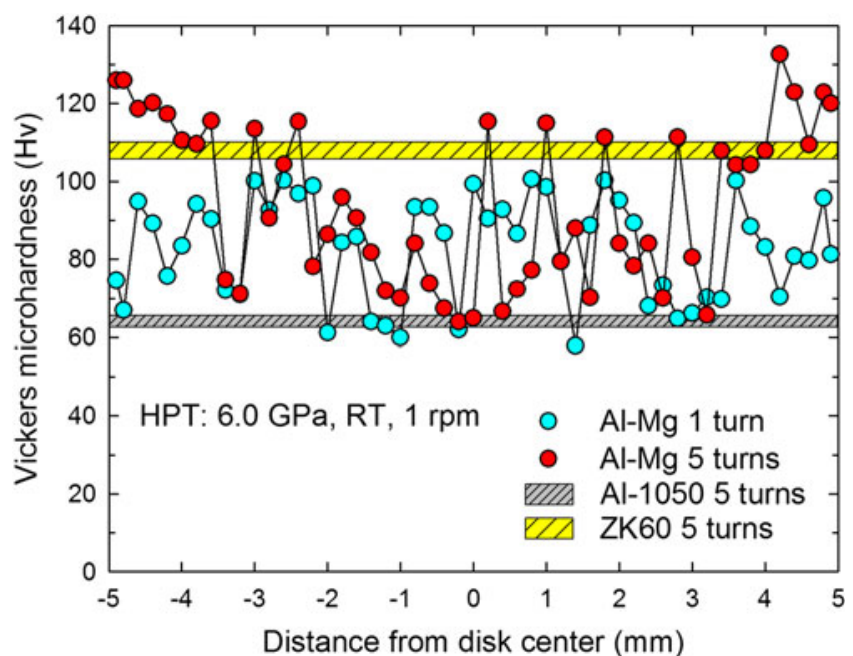

FIG. 6. The hardness variations along the diameters of the $\mathrm{Al}-\mathrm{Mg}$ disks after HPT for 1 and 5 turns: the map includes the hardness ranges of $\sim 63-65$ for Al-1050 (Ref. 36) and $\sim 105-110$ for the ZK60 alloy $^{37}$ after HPT for 5 turns in gray and yellow markers, respectively.

to note that even the low hardness of $H_{\mathrm{v}} \approx 60$ after 1 turn in the $\mathrm{Al}-\mathrm{Mg}$ system is much higher than the minimum hardness of $\sim 45$ for Al-1050 after HPT for 1 turn under $6.0 \mathrm{GPa}^{36}$ Thus, although there is no significant high hardness, the multi-layered structure of the $\mathrm{Al}-\mathrm{Mg}$ alloy system leads to a rise in the minimum hardness limit after HPT for 1 turn. After 5 turns of HPT, there is no change in hardness at the central region because the multi-layered structure remains whereas there is an exceptional hardness at $r$ $>4 \mathrm{~mm}$ including the maximum of $H_{\mathrm{v}} \approx 135$. This high hardness is higher than the highest attainable value of $\sim 110$ for the ZK60 alloy after HPT for 5 turns and the area exhibiting high hardness is coincident with the region showing the homogeneous distribution of fine $\mathrm{Mg}$ phases within the $\mathrm{Al}$ matrix as shown in Fig. 2.

Figure 7(a) shows the XRD patterns for, in descending order, the Al-Mg disk, Al-1050 and ZK60, respectively, after HPT under $6.0 \mathrm{GPa}$ for 5 turns at room temperature and Fig. 7(b) shows the $\mathrm{Al}-\mathrm{Mg}$ alloy over the limited angular range for 2 theta of $30^{\circ}-60^{\circ}$. It is apparent from Fig. 7(a) that the processed $\mathrm{Al}-\mathrm{Mg}$ disk has an XRD pattern that is very similar to Al-1050 but there are weak peaks of pure $\mathrm{Mg}$ on the $(10 \overline{1} 0)$ prism plane, (0002) basal plane, and (1011) pyramidal plane which are also visible in Fig. 7(b). In addition, an analysis of the relative peak intensities in Fig. 7(b) shows evidence for the formation of a $\beta-\mathrm{Al}_{3} \mathrm{Mg}_{2}$ intermetallic compound in the $\mathrm{Al}-\mathrm{Mg}$ disk after HPT for 5 turns. It should be mentioned that the XRD measurements were repeated several times at different surfaces by polishing the disk surfaces, thus corresponding to different sections in the height direction, but the
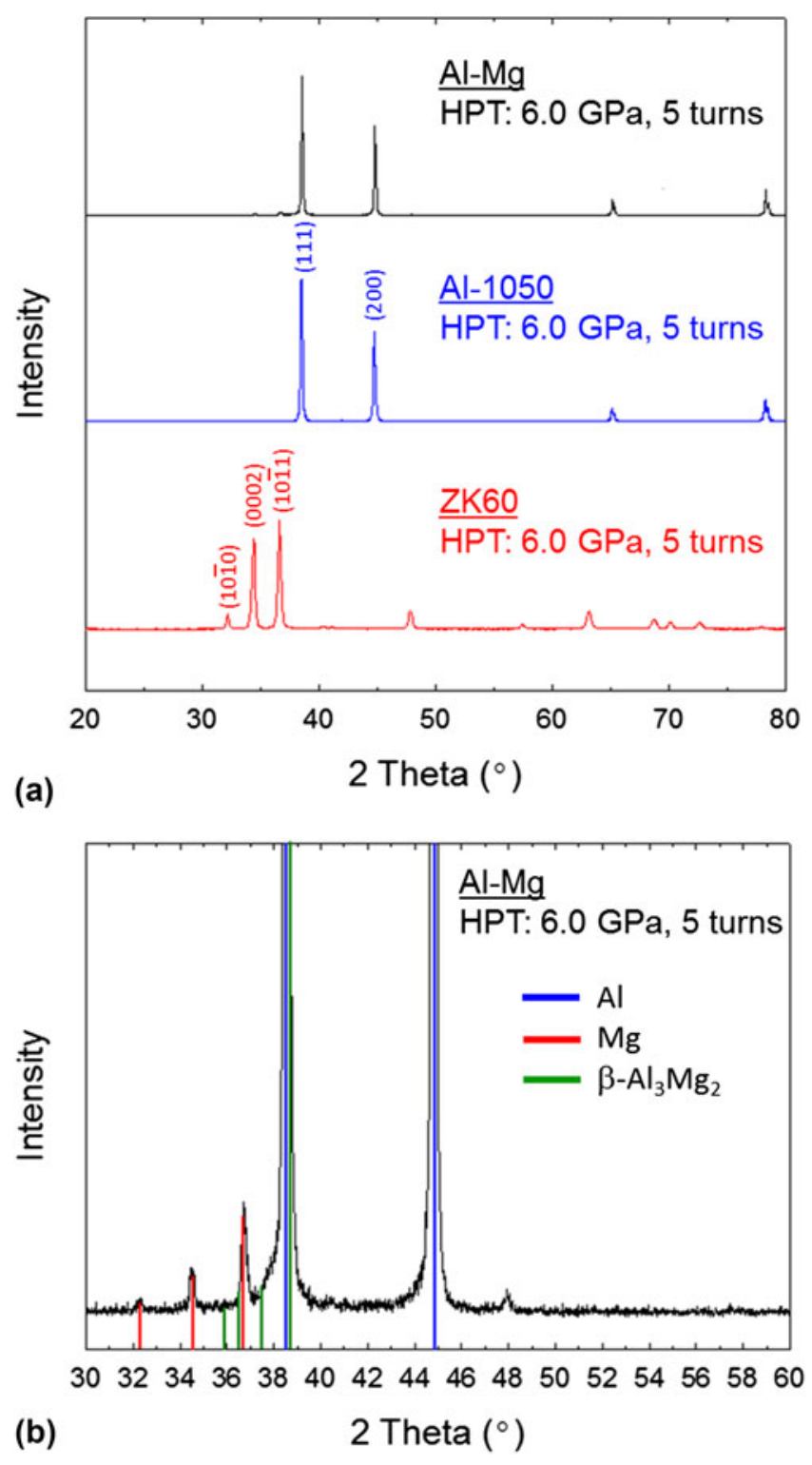

FIG. 7. (a) The XRD patterns showing, in descending order, the $\mathrm{Al}-\mathrm{Mg}, \mathrm{Al}-1050$ and ZK60 disks processed by HPT under a pressure of $6.0 \mathrm{GPa}$ for 5 turns and (b) the XRD pattern over a limited 2 theta angular range for the $\mathrm{Al}-\mathrm{Mg}$ disk after processing by HPT under a pressure of $6.0 \mathrm{GPa}$ for 5 turns.

$\beta-\mathrm{Al}_{3} \mathrm{Mg}_{2}$ was rarely observed in these measurements. This suggests that the amount of $\beta-\mathrm{Al}_{3} \mathrm{Mg}_{2}$ is less than the detectable limit of $\sim 5 \mathrm{vol} \%$ in the total measured region. The intermetallic $\beta-\mathrm{Al}_{3} \mathrm{Mg}_{2}$ was also observed earlier as very fine decomposed dispersions in $\mathrm{Al}-5 \%$ $\mathrm{Mg}$ and $\mathrm{Al}-10 \% \mathrm{Mg}$ solid solution alloys when processing by HPT at room temperature under a pressure of $5.0 \mathrm{GPa}$ for 5 turns ${ }^{40,41}$ but it was not observed in a cryomilled $\mathrm{Al}-7.5 \% \mathrm{Mg}$ alloy consolidated by HPT at room temperature at $6.0 \mathrm{GPa}$ for up to 5 turns. $^{42}$ 


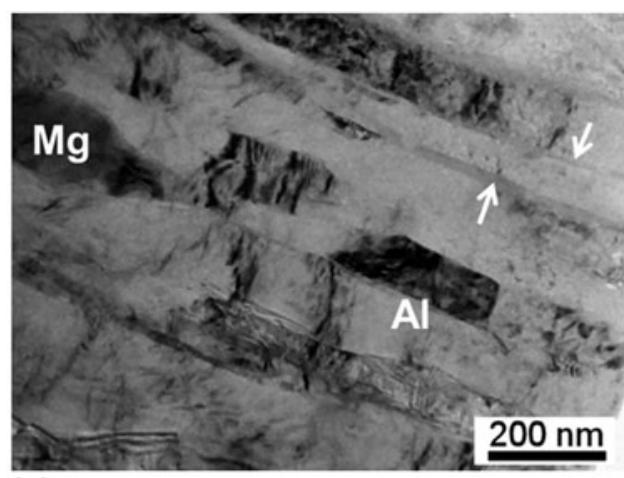

(a)

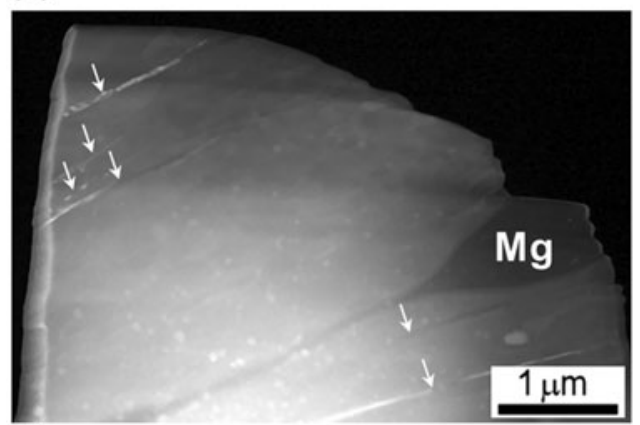

(b)

FIG. 8. A TEM bright-field image taken at the disk edge after HPT for 5 turns in (a) high magnification ${ }^{30}$ and (b) low magnification showing a layered microstructure consisting of an $\mathrm{Al}$ matrix region including one visible $\mathrm{Mg}$ phase and thin layers of $\beta-\mathrm{Al} 3 \mathrm{Mg} 2$.

\section{Formation of a nanocomposite}

Figure 8 shows a TEM bright-field image in (a) high magnification $^{30}$ and (b) low magnification taken at the edge of the Al-Mg multi-layered disk after HPT for 5 turns. From Fig. 8(a), it is apparent that much of the $\mathrm{Al}$ matrix phase consists of a layered structure with thicknesses of $\sim 90-120 \mathrm{~nm}$ and these layers contain numerous dislocations subdividing these layers in a vertical sense. The Mg phase labeled in the image has a thickness of $\sim 150 \mathrm{~nm}$ and it has a homogeneous bonding interface without any visible voids. The majority of the measurement region consists of an $\mathrm{Al}$ matrix phase and there are several thin layers with an average thickness of $\sim 20 \mathrm{~nm}$ as indicated by the white arrows in Fig. 8(a). An average grain size, $d$, of $\sim 190 \mathrm{~nm}$ was observed in the $\mathrm{Al}$ matrix at the edge of the Al-Mg multi-layered disk after 5 turns. It is important to note that these thin layers are not visible at the interfaces of the $\mathrm{Al}$ and $\mathrm{Mg}$ phases but instead they form within the $\mathrm{Al}$ matrix phase. Specifically, the $\beta-\mathrm{Al}_{3} \mathrm{Mg}_{2}$ phase is formed as thin layers with a very small amount as demonstrated in the XRD analysis and there was no evidence for the formation of a lamellar structure. This is well documented by Fig. 8(b) showing the TEM sample tip after FIB of the 5-turn disk. The thin layers denoted by the white arrows are the $\beta-\mathrm{Al}_{3} \mathrm{Mg}_{2}$ and the large gray phase is a Mg-rich phase which is shown in Fig. 8(a). It is apparent that the $\beta-\mathrm{Al}_{3} \mathrm{Mg}_{2}$ thin layers are distributed irregularly within the $\mathrm{Al}$ matrix and some show the discontinuities of the thin layers.

A compositional examination was conducted in STEM mode in the region including the randomly distributed thin layers present in Fig. 8(b) where a dark-field image within the enclosed measurement region marked by a red line is presented in Fig. 9(a) and Figs. 9(b)-9(d) show the corresponding compositional maps for $\mathrm{Al}, \mathrm{Mg}$, and $\mathrm{O}$ atoms, respectively, taken at the edge of the $\mathrm{Al}-\mathrm{Mg}$ multi-layered disk after HPT through 5 turns. Several thin layers are visible in Fig. 9 and these thin layers exist within the $\mathrm{Al}$ matrix. It is apparent that these thin layers are composed of both $\mathrm{Al}$ and $\mathrm{Mg}$ atoms and these atoms are homogeneously distributed as demonstrated in Figs. 9(b) and 9(c). Moreover, Fig. 9(d) shows there is no difference in the amount of $\mathrm{O}$ at the location of the thin layers so that the thin layers are not the oxide phase. A detailed analysis of the chemical composition was conducted at a thin layer in the 5-turn disk and the measurement location is marked as spectrum 1 in the dark-filed TEM image in Fig. 10 where there is a visible $\mathrm{Mg}$ phase. The measured composition records $\sim 64.01$ at. $\% \mathrm{Al}$ and $\sim 31.43$ at. $\% \mathrm{Mg}$ with small amounts of $\mathrm{O}, \mathrm{Zn}$ and $\mathrm{Zr}$ of $4.21,0.32$ and 0.02 at.\%, respectively, and, following conventional practice, ${ }^{43}$ it is defined as the intermetallic compound $\beta-\mathrm{Al}_{3} \mathrm{Mg}_{2}$. Thereby, the HPT processing of $\mathrm{Al}$ and $\mathrm{Mg}$ alloys demonstrates the formation of an intermetallic-based metal matrix nanocomposite. It should be noted that the quantitative analysis was conducted close to the thin layer but within the $\mathrm{Al}$ matrix and it demonstrated there was $\sim 0.2 \mathrm{wt} \% \mathrm{Mg}$ in the $\mathrm{Al}$ matrix which is much higher than the value of $\sim 0.05 \mathrm{wt} \% \mathrm{Mg}$ in the commercial-grade Al-1050 alloy. However, it is lower than the maximum solubility of $1.8 \mathrm{wt} \% \mathrm{Mg}$ in $\mathrm{Al}$ at room temperature and thus there is no evidence for the formation of a supersaturated solid solution in the $\mathrm{Al}-\mathrm{Mg}$ alloy system after HPT for 5 turns.

There is a Mg phase with a thickness of $\sim 500 \mathrm{~nm}$ and the homogeneous interface of $\mathrm{Al}$ and $\mathrm{Mg}$ phases without any voiding in Fig. 10 where the dark-field image displays a thickness of the interface of $\sim 20 \mathrm{~nm}$. Thus, it appears that there is homogeneous diffusion bonding at the $\mathrm{Al} / \mathrm{Mg}$ interface with a diffusion length of $\sim 20 \mathrm{~nm}$ and with a fine dispersion of the $\mathrm{Mg}$ phase within the $\mathrm{Al}$ matrix at the disk edge after HPT processing through 5 turns.

\section{DISCUSSION}

\section{A. Potential for using HPT to achieve nanocomposite materials}

The results described in this report provide the first comprehensive study demonstrating the formation of 


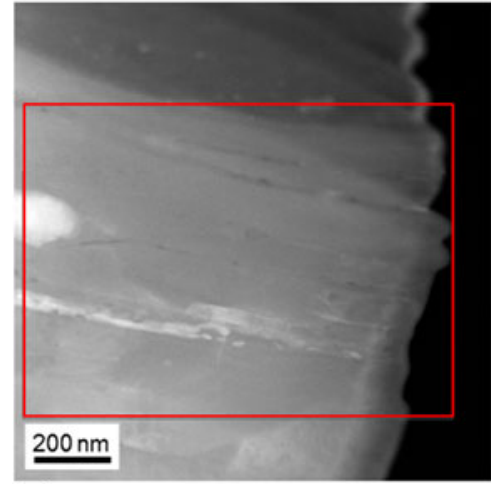

(a)

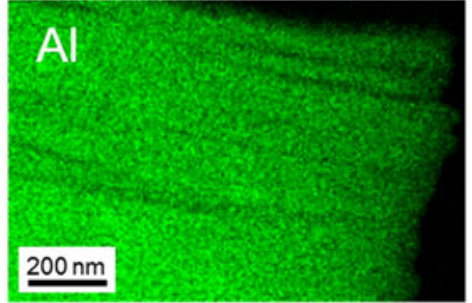

(b)

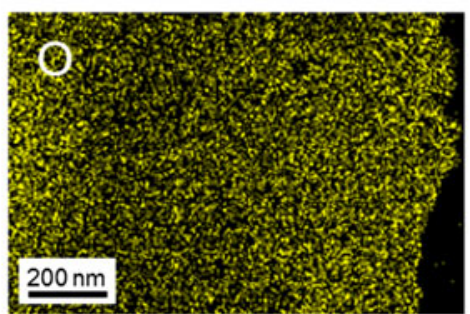

(d)

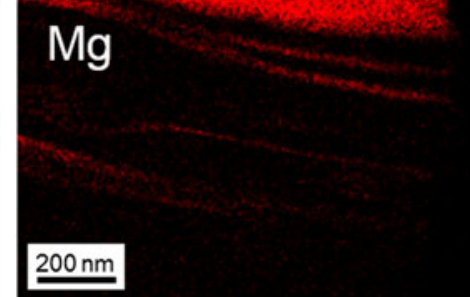

(c)

FIG. 9. (a) A TEM dark-field image and the corresponding compositional maps of (b) $\mathrm{Al}$, (c) $\mathrm{Mg}$ and (d) $\mathrm{O}$ atoms taken at the edge of the $\mathrm{Al}-\mathrm{Mg}$ disk after HPT under a pressure of $6.0 \mathrm{GPa}$ for 5 turns.

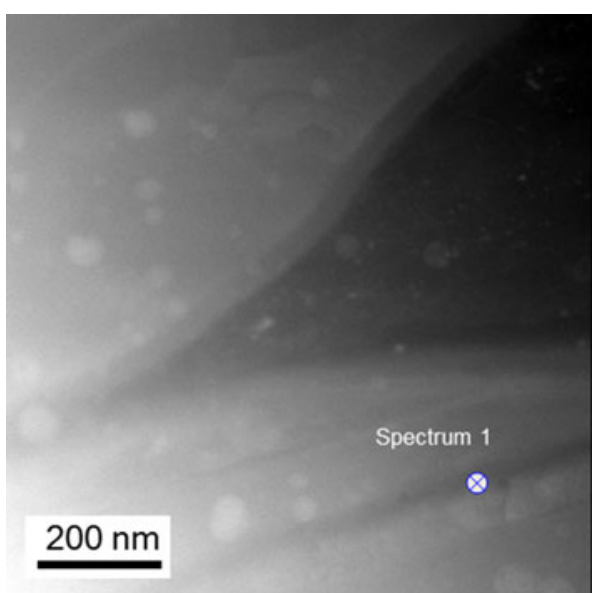

FIG. 10. A TEM dark-field image showing the point for the chemical composition measurement.

an intermetallic-based $\mathrm{Al}$ matrix nanocomposite through the processing of disks of commercial $\mathrm{Al}$ and $\mathrm{Mg}$ alloys using conventional quasi-constrained HPT at room temperature. In practice, processing by HPT for 5 turns leads to the unique formation of a multi-layered $\mathrm{Al}-\mathrm{Mg}$ material at the disk center without the development of any visible voids. The results display a fine dispersion of a magnesium-rich phase in the nanostructured $\mathrm{Al}$ matrix with rapid diffusion of $\mathrm{Mg}$ in the $\mathrm{Al}$ synthesizing intermetallic thin layers and thereby leading to the formation of a nanocomposite in the peripheral regions of the disk. It should be noted that the introduction of fine dispersions of dissimilar metal phases is not common after processing by ARB processing unless the sheet thickness of the hard metal is specially prepared so that it is much less than the thickness of the soft metal. ${ }^{35,44-47}$
The intermetallic compound, $\beta-\mathrm{Al}_{3} \mathrm{Mg}_{2}$, has a low density of $\sim 2.25 \mathrm{~g} / \mathrm{cm}^{3}$ (Ref. 48) and a measured high upper yield stress of $\sim 780 \mathrm{MPa}$ at a temperature of $498 \mathrm{~K}$ when testing at a strain rate of $10^{-4} \mathrm{~s}^{-1}$ (Ref. 49) so that it has an excellent potential for serving as a reinforcing agent in $\mathrm{Al}$ matrix composites for increasing the hardness, the compressive strength and the wear resistance. ${ }^{50}$ In the present experiments, as shown in Figs. 5 and 6, the peripheral region in the processed $\mathrm{Al}-\mathrm{Mg}$ nanocomposite exhibits a higher hardness than in the processed Al-1050 alloy or the ZK60 alloy and this increased hardness is due to the presence of the nano-layered intermetallic compound. Thus, the $\beta-\mathrm{Al}_{3} \mathrm{Mg}_{2}$ thin layers in the nanostructured $\mathrm{Al}-\mathrm{Mg}$ alloy system lead to the formation of an intermetallic-based $\mathrm{Al}$ matrix nanocomposite after processing by HPT through 5 turns. In a recent study it was shown that an additional 5 turns will provide exceptional hardness in the hybrid Al-Mg system by HPT due to the combination of further grain refinement, solution strengthening, and precipitation hardening. ${ }^{30}$ It should be noted that there are at present some limited reports of the production of $\mathrm{Al} / \mathrm{Mg} / \mathrm{Al}$ layered sheets which demonstrate the formation of intermetallic compounds by hot or warm rolling and ARB processing ${ }^{23-25,45}$ but there are no reports of either a nanostructured matrix phase or nano-scale intermetallic phases.

The present study demonstrates a potential for using HPT at ambient temperature for synthesizing, over a very short period of time, an intermetallic-based metal matrix nanocomposite in a multi-layered structure having exceptionally high strength through diffusion bonding in the $\mathrm{Al}-\mathrm{Mg}$ system. It is worth noting that the HPT procedure introduces very high straining within samples but the final bulk solid contains a gradient-type nanostructure. Recently, this type of microstructure is well recognized in many biological 
systems ${ }^{51}$ and the microstructure is also focused as a new type of structure in engineering materials having a potential for exhibiting excellent mechanical properties. ${ }^{52-54}$ Accordingly, the present study demonstrates significant results and a great potential for using SPD processing for fabricating high-strength nanocomposites. More research is now necessary to confirm the capability of using this powerful technique for synthesizing other metallic systems.

\section{B. The kinetics of diffusion bonding and the growth of an intermetallic compound}

In this investigation, the interfaces between the $\mathrm{Al}$ and $\mathrm{Mg}$ phases are homogeneously bonded throughout the disk after HPT for 5 turns at room temperature. Different diffusion lengths were measured at different locations and the diffusion length, $x$, was evaluated though the relationship

$$
x=2 \sqrt{D t},
$$

where $D$ is the diffusion coefficient $\left[=D_{\mathrm{o}} \exp (-Q / R T)\right.$ where $D_{\mathrm{o}}$ is a frequency factor, $Q$ is the activation energy, $R$ is the gas constant, and $T$ is the absolute temperature] and $t$ is the processing time. Specifically, it is possible to take two examples of $x \approx 2-5 \mu \mathrm{m}$ for the relatively large $\mathrm{Mg}$ phase in the central region of the disk as shown in Fig. 2 and $x \approx 20 \mathrm{~nm}$ for the fine $\mathrm{Mg}$ phase at the edge of the disk as shown in Fig. 10. Using Eq. (2), it then follows that the values of $D$ are estimated in the range of $\sim 3.0 \times 10^{-19}$ to $\sim 10^{-14} \mathrm{~m}^{2} / \mathrm{s}$ after $t=300 \mathrm{~s}$ for 5 turns of HPT at $1 \mathrm{rpm}$.

When synthesizing a new alloy system from separate solid metals by diffusion bonding under a high pressure, it is reasonable to consider the interdiffusion of an $\mathrm{Al}-\mathrm{Mg}$ binary system where the $\mathrm{Mg}$ atoms are accelerated to diffuse into the $\mathrm{Al}$ matrix by the effect of the imposed hydraulic pressure. In practice, the compressive pressure is expected to reduce the activation energies for diffusion processes so that, by using fundamental parameters, ${ }^{55}$ the modified diffusivity, $D_{\mathrm{m}}$, is given in the following form:

$$
D_{\mathrm{m}}=D_{\mathrm{o}} \exp \left[-\left(Q-\sigma_{y} \times \Omega_{0}\right) / R T\right],
$$

where $\sigma_{y}$ is the yield stress and $\Omega_{0}$ is the molar volume of $\mathrm{Mg}$ $\left(\sim 1.4 \times 10^{-5} \mathrm{~m}^{3} / \mathrm{mol}\right)$. Thus, Eq. (3) is applicable for calculating the diffusivities of $\mathrm{Mg}$ in $\mathrm{Al}$ by both grain boundary diffusion and bulk diffusion so that the effective diffusion coefficient under a hydraulic stress, $D_{\text {eff }}$, is obtained using the coefficients of grain boundary diffusion, $D_{\mathrm{gb}}$, and bulk diffusion, $D_{\mathrm{l}}$, in the following form:

$$
D_{\text {eff }}=\left\{f_{\mathrm{gb}} \times D_{\mathrm{gb}}\right\}+\left\{\left(1-f_{\mathrm{gb}}\right) \times D_{1}\right\} \quad,
$$

where $f_{\mathrm{gb}}$ is the volume fraction of grain boundaries ${ }^{56}$ given by $f_{\mathrm{gb}}=3 s \delta / d$, where $s$ is the grain boundary segregation factor generally taken as $\sim 1$ and $\delta$ is the grain boundary width of $\sim 0.5 \mathrm{~nm}$. Using $D_{\mathrm{o}(\mathrm{gb})} \approx 1.4 \times 10^{-4} \mathrm{~m}^{2} / \mathrm{s}$ and $D_{\mathrm{o}(\mathrm{l})} \approx 1.24 \times 10^{-4} \mathrm{~m}^{2} / \mathrm{s}$ for grain boundary diffusion and bulk diffusion of $\mathrm{Mg},{ }^{55}$ respectively, and the presence of stresses up to $\sim 0.45 \mathrm{GPa}$ (equivalent to $H_{\mathrm{v}} \approx 135$ ) and applying grain sizes of $\sim 190 \mathrm{~nm}$, Eqs. (3) and (4) give $D_{\text {eff }}$ of $1.2 \times 10^{-18}-1.5 \times 10^{-14} \mathrm{~m}^{2} / \mathrm{s}$ at $300-423 \mathrm{~K}$. Considering this level of inevitable temperature rise during HPT attributed to high friction between the sample and anvils, ${ }^{57,58}$ the estimated effective diffusivity of $\mathrm{Mg}$ under the compressive stress is in excellent agreement with the value of $D$ for diffusion bonding of $\mathrm{Al}$ and $\mathrm{Mg}$ phases calculated by Eq. (2). It is also worthwhile noting that these values calculated for $D$ and estimated for $D_{\text {eff }}$ are reasonably consistent with an earlier report estimating the interdiffusion coefficient in $\mathrm{Al}-\mathrm{Mg}$ binary diffusion couples even though these earlier measurements were conducted without any compressive pressure but instead at high temperatures of $653-693 \mathrm{~K}$ for up to $t=100 \mathrm{~h}^{59}$

Furthermore, the present estimation of effective diffusivity also derives an activation energy of $Q \approx 80 \mathrm{~kJ} / \mathrm{mol}$ for diffusion bonding of the $\mathrm{Al}$ and $\mathrm{Mg}$ phases in the $\mathrm{Al}-\mathrm{Mg}$ system through HPT. As suggested in earlier reports, ${ }^{19,28}$ the estimated activation energy should be of the order of $\sim 1 / 2$ to $\sim 2 / 3$ of the activation energies of 142 and $135 \mathrm{~kJ} / \mathrm{mol}$ for lattice diffusion of $\mathrm{Al}$ and $\mathrm{Mg},{ }^{55}$ respectively, so that the activation energy is therefore comparable to the value for surface diffusion. This very rapid diffusivity is due to the high population of lattice defects, and especially it is due to the presence of vacancies and vacancy agglomerates which are introduced in metals when processing by SPD techniques such as equal-channel angular pressing ${ }^{60}$ and HPT. ${ }^{61}$

Accordingly, it appears that the rapid diffusion forms nano-layers of the intermetallic compound $\beta-\mathrm{Al}_{3} \mathrm{Mg}_{2}$ in the nanostructured $\mathrm{Al}$ matrix near the edge of the disk after HPT for 5 turns. The growth kinetics of intermetallic phases under diffusion growth may be calculated from the following relationship ${ }^{62}$ :

$$
Y=k \sqrt{t},
$$

where $Y$ is the thickness of the intermetallic layer, $k$ is the growth constant, and $t$ is the time of formation which is equivalent to the processing time. The temperature dependence of the growth of the intermetallic layers should follow an Arrhenius relation so that $k$ is expressed by a relationship of the form

$$
k=k_{\mathrm{o}} \exp \left(-\frac{Q}{R T}\right),
$$

where $k_{0}$ is a pre-exponential factor.

The present experiments reveal an intermetallic layer thickness of $Y \approx 20 \mathrm{~nm}$ after $t=300 \mathrm{~s}$ for 5 turns by HPT as shown in Figs. 8-10 and, using Eq. (5), this leads to 
a growth constant of $k \approx 1.2 \times 10^{-9} \mathrm{~m}^{2} / \mathrm{s}$ for the $\beta-\mathrm{Al}_{3} \mathrm{Mg}_{2}$ nano-layers. In addition, using Eq. (6) with $Q \approx 80 \mathrm{~kJ} / \mathrm{mol}$ and taking temperatures from 300 to $423 \mathrm{~K}$ to allow for processing at room temperature and the temperature rise during HPT processing, the pre-exponential constant is estimated as $k_{0} \approx 10^{2}-10^{5} \mathrm{~m}^{2} / \mathrm{s}$ for the $\beta-\mathrm{Al}_{3} \mathrm{Mg}_{2}$ nano-layers under these experimental conditions. The activation energy for formation of the $\beta-\mathrm{Al}_{3} \mathrm{Mg}_{2}$ nanolayers of $Q \approx 80 \mathrm{~kJ} / \mathrm{mol}$ is consistent with the reported value of $\sim 86 \mathrm{~kJ} / \mathrm{mol}$ for the formation of the $\beta-\mathrm{Al}_{3} \mathrm{Mg}_{2}$ intermetallic phase using a solid-to-solid diffusion couple technique at elevated temperatures of $573-673 \mathrm{~K}^{62,63}$ The measured $k_{0}$ value in the present analysis is much higher than the reported value of $k_{0} \approx 2 \times 10^{-6} \mathrm{~m}^{2} / \mathrm{s}^{62,63}$ and this difference is due to the rapid diffusion associated with the enhanced concentration of vacancy-type defects due to the HPT processing. This conclusion agrees with recent reports demonstrating that the enhanced atomic diffusion in nanostructured material after equal-channel angular pressing (ECAP) is attributed to the introduction of extra free volumes due to the high population of lattice defects in the nanostructure. ${ }^{64,65}$

It is reasonable to conclude from these results that the deformation-induced rapid diffusion not only bonds the $\mathrm{Al}$ and $\mathrm{Mg}$ phases to give a multi-layered structure but also becomes the driving force for the formation of the $\beta-\mathrm{Al}_{3} \mathrm{Mg}_{2}$ intermetallic nano-layers at room temperature. Thus, an intermetallic-based $\mathrm{Al}$ matrix nanocomposite is introduced around the periphery of the $\mathrm{Al}-\mathrm{Mg}$ alloy during processing by HPT through 5 turns. The present results are unusual and they suggest there may be a considerable potential for using processing by HPT to synthesize new alloy systems from simple metals and alloys. Further investigations are now needed to fully explore the potential and limitations of this approach and especially to examine the detailed microstructural changes that may be produced in different metal systems.

\section{SUMMARY AND CONCLUSIONS}

(1) Conventional HPT processing was performed successfully by processing through 5 turns at room temperature to produce an $\mathrm{Al}-\mathrm{Mg}$ alloy system having unique microstructural distribution within the disk through the diffusion bonding of separate $\mathrm{Al}$ and $\mathrm{Mg}$ disks. Following processing, the microhardness and the deformed microstructure were examined, including the compositions at selected areas, to evaluate the feasibility of using HPT for the formation of intermetallic compounds through diffusion bonding.

(2) The results demonstrate the formation of an intermetallic compound, $\beta-\mathrm{Al}_{3} \mathrm{Mg}_{2}$, in the form of nano-layers in the $\mathrm{Al}$ matrix and the synthesis of an intermetallic-based Al matrix nanocomposite in the highly deformed region around the periphery of the disk after processing by HPT. Overall, different scales of an $\mathrm{Al}-\mathrm{Mg}$ multi-layered structure are formed with large phases at the disk center and with phases in the submicrometer level at the disk edge after processing for 5 turns.

(3) The effective diffusion of $\mathrm{Mg}$ atoms in the $\mathrm{Al}$ matrix is estimated under compression and the value is in excellent agreement with the calculated diffusivity for diffusion bonding of $\mathrm{Al}$ and $\mathrm{Mg}$ phases in the processed $\mathrm{Al}-\mathrm{Mg}$ alloy system. Moreover, the rapid diffusion leads to a low activation energy for diffusion bonding and this activation energy is also responsible for the formation of a $\beta-\mathrm{Al}_{3} \mathrm{Mg}_{2}$ intermetallic compound. This rapid diffusion requiring low activation energy is due to the severely deformed microstructure and the excess of vacancy-type defects introduced by HPT processing.

(4) The results demonstrate a considerable potential for using HPT processing for the development of new alloy systems. Further investigations are now needed to fully explore these possibilities.

\section{ACKNOWLEDGMENTS}

This work was supported in part by the NRF Korea funded by MoE under Grant No. NRF-2014R1A1A2057697 (M.K.), in part by the NRF Korea funded by MSIP under Grant No. NRF-2012R1A1A1012983 (B.A.), in part by the Russian Science Foundation under Grant No. 14-29-00199 (A.P.Z.), in part by the NSF of the United States under Grant No. DMR-1160966 and in part by the European Research Council under ERC Grant Agreement No. 267464-SPDMETALS (T.G.L.).

\section{REFERENCES}

1. R.Z. Valiev, R.K. Islamgaliev, and I.V. Alexandrov: Bulk nanostructured materials from severe plastic deformation. Prog. Mater. Sci. 45, 103 (2000).

2. A.P. Zhilyaev and T.G. Langdon: Using high-pressure torsion for metal processing: Fundamentals and applications. Prog. Mater. Sci. 53, 893 (2008).

3. R.Z. Abdulov, R.Z. Valiev, and N.A. Krasilnikov: Formation of submicrometre-grained strucure in magnesium alloy due to high plastic strains. J. Mater. Sci. Lett. 9, 1445 (1990).

4. T.G. Langdon: Twenty-five years of ultrafine-grained materials: Achieving exceptional properties through grain refinement. Acta Mater. 61, 7035 (2013).

5. R.Z. Valiev, Yu.V. Ivanisenko, E.F. Rauch, and B. Baudelet: Structure and deformation behaviour of armco iron subjected to severe plastic deformation. Acta Mater. 44, 4705 (1996).

6. H. Jiang, Y.T. Zhu, D.P. Butt, I.V. Alexandrov, and T.C. Lowe: Microstructural evolution, microhardness and thermal stability of HPT-processed Cu. Mater. Sci. Eng., A 290, 128 (2000).

7. A.P. Zhilyaev, S. Lee, G.V. Nurislamova, R.Z. Valiev, and T.G. Langdon: Microhardness and microstructural evolution in pure nickel during high-pressure torsion. Scr. Mater. 44, 2753 (2001).

8. A.P. Zhilyaev, G.V. Nurislamova, B.K. Kim, M.V. Baró, J.A. Szpunar, and T.G. Langdon: Experimental parameters 
influencing grain refinement and microstructural evolution during high-pressure torsion. Acta Mater. 51, 753 (2003).

9. Z.C. Duan, X.Z. Liao, M. Kawasaki, R.B. Figueiredo, and T.G. Langdon: Influence of high-pressure torsion on microstructural evolution in an Al-Zn-Mg-Cu alloy. J. Mater. Sci. 45, 4621 (2010).

10. N. Lugo, N. Llorca, J.M. Cabrera, and Z. Horita: Microstructures and mechanical properties of pure copper deformed severely by equal-channel angular pressing and high pressure torsion. Mater. Sci. Eng., A 477, 366 (2008).

11. A.P. Zhilyaev, A.A. Gimazov, G.I. Rabb, and T.G. Langdon: Using high-pressure torsion for the cold-consolidation of copper chips produced by machining. Mater. Sci. Eng., A 486, 123 (2008).

12. J. Wongsa-Ngam, H. Wen, and T.G. Langdon: Microstructural evolution in a $\mathrm{Cu}-\mathrm{Zr}$ alloy processed by a combination of ECAP and HPT. Mater. Sci. Eng., A 579, 126 (2013).

13. S. Sabbaghianrad and T.G. Langdon: A critical evaluation of the processing of an aluminum 7075 alloy using a combination of ECAP and HPT. Mater. Sci. Eng., A 596, 52 (2014).

14. J.M. Cubero-Sesin and Z. Horita: Powder consolidation of Al-10 wt $\%$ Fe alloy by high-pressure torsion. Mater. Sci. Eng., A 558, 462 (2012).

15. K. Kaneko, T. Hata, T. Tokunaga, and Z. Horita: Fabrication and characterization of supersaturated $\mathrm{Al}-\mathrm{Mg}$ alloys by severe plastic deformation and their mechanical properties. Mater. Trans. 50, 76 (2009).

16. K. Edalati, S. Toh, M. Watanabe, and Z. Horita: In situ production of bulk intermetallic-based nanocomposites and nanostructured intermetallics by high-pressure torsion. Scr. Mater. 66, 386 (2012).

17. K. Edalati, S. Toh, H. Iwaoka, M. Watanabe, Z. Horita, D. Kashioka, K. Kishida, and H. Inui: Ultrahigh strength and high plasticity in TiAl intermetallics with bimodal grain structure and nanotwins. Scr. Mater. 67, 814 (2012).

18. K.V. Rajulapati, R.O. Scattergood, K.L. Murty, Z. Horita, T.G. Langdon, and C.C. Koch: Mechanical properties of bulk nanocrystalline aluminum-tungsten alloys. Metall. Mater. Trans. A 39, 2528 (2008).

19. K. Edalati, S. Toh, H. Iwaoka, and Z. Horita: Microstructural characteristics of tungsten-base nanocomposites produced from micropowders by high-pressure torsion. Acta Mater. 60, 3885 (2012).

20. P. Jenei, J. Gubicza, E.Y. Yoon, and H.S. Kim: X-ray diffraction study on the microstructure of a $\mathrm{Mg}-\mathrm{Zn}-\mathrm{Y}$ alloy consolidated by high-pressure torsion. J. Alloys Compd. 539, 32 (2012).

21. X.K. Peng, R. Wuhrer, G. Heness, and W.Y. Yeung: On the interface development and fracture behaviour of roll bonded copper/aluminium metal laminates. J. Mater. Sci. 34, 2029 (1999).

22. H. Sieber, J.S. Park, J. Weissmüller, and J.H. Perepezko: Structural evolution and phase formation in cold-rolled aluminum-nickel multilayers. Acta Mater. 49, 1139 (2001).

23. X.P. Zhang, T.H. Yang, S. Castagne, and J.T. Wang: Microstructure; bonding strength and thickness ratio of $\mathrm{Al} / \mathrm{Mg} / \mathrm{Al}$ alloy laminated composites prepared by hot rolling. Mater. Sci. Eng., A 528, 1954 (2011).

24. A. Macwan, X.Q. Jiang, C. Li, and D.L. Chen: Effect of annealing on interface microstructures and tensile properties of rolled $\mathrm{Al} / \mathrm{Mg} / \mathrm{Al}$ tri-layer clad sheets. Mater. Sci. Eng., A 587, 344 (2013).

25. K.S. Lee, Y.S. Lee, and Y.N. Kwon: Influence of secondary warm rolling on the interface microstructure and mechanical properties of a roll-bonded three-ply $\mathrm{Al} / \mathrm{Mg} / \mathrm{Al}$ sheet. Mater. Sci. Eng., A 606, 205 (2014).

26. Y. Saito, N. Tsuji, H. Utsunomiya, T. Sakai, and R.G. Hong: Ultra-fine grained bulk aluminum produced by accumulative roll-bonding (ARB) process. Scr. Mater. 39, 1221 (1998).
27. B. Beausir, J. Scharnweber, J. Jaschinski, H-G. Brokmeier, C-G. Oertel, and W. Skrotzki: Plastic anisotropy of ultrafine grained aluminium alloys produced by accumulative roll bonding. Mater. Sci. Eng., A 527, 3271 (2010).

28. K. Oh-ishi, K. Edalati, H.S. Kim, K. Hono, and Z. Horita: Highpressure torsion for enhanced atomic diffusion and promoting solid-state reactions in the aluminum-copper system. Acta Mater. 61, 3482 (2012).

29. O. Bouaziz, H.S. Kim, and Y. Estrin: Architecturing of metal-based composites with concurrent nanostructuring: A new paradigm of materials design. Adv. Eng. Mater. 15, 336 (2013).

30. B. Ahn, A.P. Zhilyaev, H-J. Lee, M. Kawasaki, and T.G. Langdon: Rapid synthesis of an extra hard metal matrix nanocomposite at ambient temperature. Mater. Sci. Eng., A 635, 109 (2015).

31. R.B. Figueiredo, P.R. Cetlin, and T.G. Langdon: Using finite element modeling to examine the flow processes in quasi-constrained high-pressure torsion. Mater. Sci. Eng., A 528, 8198 (2011).

32. R.B. Figueiredo, P.H.R. Pereira, M.T.P. Aguilar, P.R. Cetlin, and T.G. Langdon: Using finite element modeling to examine the temperature distribution in quasi-constrained high-pressure torsion. Acta Mater. 60, 3190 (2012).

33. M. Kawasaki and T.G. Langdon: The significance of strain reversals during processing by high-pressure torsion. Mater. Sci. Eng., A 498, 341 (2008).

34. I.D. Choi, D.K. Matlock, and D.L. Olson: An analysis of diffusion-induced porosity in $\mathrm{Cu}-\mathrm{Ni}$ laminate composites. Mater. Sci. Eng., A 124, L15 (1990).

35. L. Ghalandari and M.M. Moshksar: High-strength and highconductive $\mathrm{Cu} / \mathrm{Ag}$ multilayer produced by ARB. J. Alloys Compd. 506, 172 (2010).

36. M. Kawasaki, S.N. Alhajeri, C. Xu, and T.G. Langdon: The development of hardness homogeneity in pure aluminum and aluminum alloy disks processed by high-pressure torsion. Mater. Sci. Eng., A 529, 345 (2011).

37. H-J. Lee, S.K. Lee, K.H. Jung, G.A. Lee, B. Ahn, M. Kawasaki, and T.G. Langdon: Evolution in hardness and texture of a ZK60A magnesium alloy processed by high-pressure torsion. Mater. Sci. Eng., A 630, 90 (2015).

38. M. Kawasaki: Different models of hardness evolution in ultrafinegrained materials processed by high-pressure torsion. J. Mater. Sci. 49, 18 (2014)

39. M. Kawasaki, R.B. Figueiredo, Y. Huang, and T.G. Langdon: Interpretation of hardness evolution in metals processed by highpressure torsion. J. Mater. Sci. 49, 6586 (2014).

40. B.B. Straumal, B. Baretzky, A.A. Mazilkin, F. Phillipp, O.A. Kogtenkova, M.N. Volkov, and R.Z. Valiev: Formation of nanograined structure and decomposition of supersaturated solid solution during high pressure torsion of $\mathrm{Al}-\mathrm{Zn}$ and Al-Mg alloys. Acta Mater. 52, 4469 (2004).

41. A.A. Mazilkin, B.B. Straumal, E. Rabkin, B. Baretzky, S. Enders, S.G. Protasova, O.A. Kogtenkova, and R.Z. Valiev: Softening of nanostructured $\mathrm{Al}-\mathrm{Zn}$ and $\mathrm{Al}-\mathrm{Mg}$ alloys after severe plastic deformation. Acta Mater. 54, 3933 (2006).

42. Z. Lee, F. Zhou, R.Z. Valiev, E.J. Lavernia, and S.R. Nutt: Microstructure and microhardness of cryomilled bulk nanocrystalline $\mathrm{Al}-7.5 \% \mathrm{Mg}$ alloy consolidated by high pressure torsion. Scr. Mater. 51, 209 (2004).

43. A.A. Nayeb-Hashemi and J.B. Clark: Phase Diagrams of Binary Magnesium Alloys (ASM International, Metals Park, OH, 1988); p. 18.

44. M. Eizadjou, A. Kazemi Talachi, H. Danesh Manesh, H. Shakur Shahabi, and K. Janghorban: Investigation of structure and mechanical properties of multi-layered $\mathrm{Al} / \mathrm{Cu}$ composite produced 
by accumulative roll bonding (ARB) process. Compos. Sci. Technol.. 68, 2003 (2008).

45. M.C. Chen, C.W. Kuo, C.M. Chang, C.C. Hsieh, Y.Y. Chang, and W. Wu: Diffusion and formation of intermetallic compounds during accumulative roll-bonding of $\mathrm{Al} / \mathrm{Mg}$ alloys. Mater. Trans. 48, 2595 (2007)

46. R. Nasiri Dehsorkhi, F. Qods, and M. Tajally: Investigation on microstructure and mechanical properties of $\mathrm{Al}-\mathrm{Zn}$ composite during accumulative roll bonding (ARB) process. Mater. Sci. Eng., A 530, 63 (2011).

47. H. Chang, M.Y. Zheng, C. Xu, G.D. Fan, H.G. Brokmeier, and $\mathrm{K}$. Wu: Microstructure and mechanical properties of the $\mathrm{Mg} / \mathrm{Al}$ multilayer fabricated by accumulative roll bonding (ARB) at ambient temperature. Mater. Sci. Eng., A 543, 249 (2012).

48. S. Samson: The crystal structure of the phase $\beta \mathrm{Mg}_{2} \mathrm{Al}_{3}$. Acta Crystallogr. 19, 401 (1965).

49. S. Roitsch, M. Heggen, M. Lipiński-Chwalek, and M. Feuerbacher: Single-crystal plasticity of the complex metallic alloy phase $\beta-\mathrm{Al}-\mathrm{Mg}$. Intermetallics 15, 833 (2007).

50. A. Zolriasatein, R.A. Khosroshahi, M. Emamy, and N. Nemati: Mechanical and wear properties of $\mathrm{Al}-\mathrm{Al}_{3} \mathrm{Mg}_{2}$ nanocompoasites prepared by mechanical milling and hot pressing. Int. J. Miner., Metall. Mater. 20, 290 (2013).

51. P.Y. Chen, J. McKittrick, and M.A. Meyers: Biological materials: Functional adaptations and bioinspired designs. Prog. Mater. Sci. 57, 1492 (2012).

52. T.H. Fang, W.L. Li, N.R. Tao, and K. Lu: Revealing extraordinary intrinsic tensile plasticity in gradient nano-grained copper. Science 331, 1587 (2011).

53. X. Wu, P. Jiang, L. Chen, F. Yuan, and Y.T. Zhu: Extraordinary strain hardening by gradient structure. Proc. Natl. Acad. Sci. USA 111, 7197 (2014).

54. K. Lu: Making strong nanomaterials ductile with gradients. Science 345, 1455 (2014).

55. H.J. Frost and M.F. Ashby: Deformation-Mechanism Maps; The Plasticity and Creep of Metals and Ceramics (Pergamon Press, Oxford, UK, 1982).
56. T. Fujita, Z. Horita, and T.G. Langdon: Characteristics of diffusion in Al-Mg alloys with ultrafine grain sizes. Philos. Mag. A 82, 2249 (2002).

57. A.P. Zhilyaev, J.M. García-Infanta, F. Carreño, T.G. Langdon, and O.A. Ruano: Particle and grain growth in an Al-Si alloy during high-pressure torsion. Scr. Mater. 57, 763 (2007).

58. P.H.R. Pereira, R.B. Figueiredo, Y. Huang, P.R. Cetlin, and T.G. Langdon: Modeling the temperature rise in high-pressure torsion. Mater. Sci. Eng., A 593, 185 (2014).

59. K.N. Kulkarmi and A.A. Luo: Interdiffusion and phase growth kinetics in magnesium-aluminum binary system. J. Phase Equilib. Diffus. 34, 104 (2013).

60. E. Schafler, G. Steiner, E. Korznikova, M. Kerber, and M.J. Zehetbauer: Lattice defect investigation of ECAP-Cu by means of X-ray line profile analysis, calorimetry and electrical resistometry. Mater. Sci. Eng., A 410-411, 169 (2005).

61. D. Setman, E. Schafler, E. Korznikova, and M.J. Zehetbauer: The presence and nature of vacancy type defects in nanometals detained by severe plastic deformation. Mater. Sci. Eng., A 493, 116 (2008).

62. S. Brennan, K. Bermudez, N. Kulkarni, and Y. Sohn: Growth kinetics of $\gamma-\mathrm{Al}_{12} \mathrm{Mg}_{17}$ and $\beta-\mathrm{Al}_{3} \mathrm{Mg}_{2}$ intermetallic phases in $\mathrm{Mg}$ vs. $\mathrm{Al}$ diffusion couples. In Magnesium Technology 2011, W.H. Sillekens, S.R. Agnew, N.R. Neelameggham, and S.N. Mathaudhu eds.; TMS: Warrendale, PA, 2011; pp. 549-552.

63. S. Brennan, K. Bermudez, N. Kulkarni, and Y. Sohn: Interdiffusion in the $\mathrm{Mg}$-Al system and intrinsic diffusion in $\beta-\mathrm{Mg}_{2} \mathrm{Al}_{3}$. Metall. Mater. Trans. A 43, 4043 (2012).

64. S.V. Divinski, J. Ribbe, D. Baither, G. Schmitz, G. Reglitz, H. Rösner, K. Sato and Y. Estrin, and G. Wilde: Nano- and microscale free volume in ultrafine grained $\mathrm{Cu}-1 \mathrm{wt} \% \mathrm{~Pb}$ alloy deformed by equal channel angular pressing. Acta Mater. 57, 5706 (2009).

65. S.V. Divinski, G. Reglitz, H. Rösner, Y. Estrin, and G. Wilde: Ultra-fast diffusion channels in pure Ni severely deformed by equal-channel angular pressing. Acta Mater. 59 1974 (2011). 